\title{
Tailored Silicon/Carbon Compounds for Printed Li-Ion Anodes
}

\author{
Parvathy Anitha Sukkurji, ${ }^{[a]}$ Ibrahim Issac, ${ }^{[a]}$ Surya Abhishek Singaraju, ${ }^{[a]}$ Leonardo Velasco, $^{[a]}$ \\ Jasmin Aghassi Hagmann, ${ }^{[a, b]}$ Wolfgang Bessler, ${ }^{[c]}$ Horst Hahn, ${ }^{[a, d]}$ Miriam Botros, ${ }^{*[a]}$ and \\ Ben Breitung ${ }^{*[a, e]}$
}

Silicon (Si) has turned out to be a promising active material for next-generation lithium-ion battery anodes. Nevertheless, the issues known from $\mathrm{Si}$ as electrode material (pulverization effects, volume change etc.) are impeding the development of $\mathrm{Si}$ anodes to reach market maturity. In this study, we are investigating a possible application of $\mathrm{Si}$ anodes in low-power printed electronic applications. Tailored Si inks are produced and the impact of carbon coating on the printability and their electrochemical behavior as printed Si anodes is investigated. The printed $\mathrm{Si}$ anodes contain active material loadings that are practical for powering printed electronic devices, like electrolyte gated transistors, and are able to show high capacity retentions. A capacity of $1754 \mathrm{mAh} / \mathrm{g}_{\mathrm{si}}$ is achieved for a printed $\mathrm{Si}$ anode after 100 cycles. Additionally, the direct applicability of the printed $\mathrm{Si}$ anodes is shown by successfully powering an ink-jet printed transistor.

\section{Introduction}

Lithium-ion batteries (LIB) are today's primary energy storage devices and have been widely established especially in portable electronic devices and vehicle applications. ${ }^{[1]}$ Nevertheless, research is ongoing to develop electrode materials with even more advanced electrochemical performance with regard to

[a] P. A. Sukkurji, Dr. I. Issac, S. A. Singaraju, Dr. L. Velasco,

Prof. J. A. Hagmann, Prof. H. Hahn, Dr. M. Botros, Dr. B. Breitung

Institute of Nanotechnology,

Karlsruhe Institute of Technology (KIT)

Hermann-von-Helmholtz-Platz 1,

76344 Eggenstein-Leopoldshafen, Germany

E-mail:miriam.botros@kit.edu ben.breitung@kit.edu

[b] Prof. J. A. Hagmann

Institute of Applied Research,

Offenburg University of Applied Sciences

Badstraße 25, 77652 Offenburg,

Baden-Württemberg, Germany

[c] Prof. W. Bessler

Institute of Energy Systems Technology (INES),

Offenburg University of Applied Sciences

Badstraße 25, 77652 Offenburg,

Baden-Württemberg, Germany

[d] Prof. H. Hahn

KIT-TUD Joint Research Laboratory Nanomaterials Institute of Materials

Science

Technische Universität Darmstadt (TUD),

64206 Darmstadt, Hessen, Germany

[e] Dr. B. Breitung

Karlsruhe Nano Micro Facility,

Karlsruhe Institute of Technology

Hermann-von-Helmholtz-Platz 1 ,

76344 Eggenstein-Leopoldshafen, Germany

Supporting information for this article is available on the WWW under https://doi.org/10.1002/batt.202000052

of $\odot 2020$ The Authors. Published by Wiley-VCH Verlag GmbH \& Co. KGaA. This is an open access article under the terms of the Creative Commons Attribution Non-Commercial License, which permits use, distribution and reproduction in any medium, provided the original work is properly cited and is not used for commercial purposes. higher capacities, energy densities, capacity retentions etc.. ${ }^{[2]}$ One of the most promising electrode materials, with a very high theoretical capacity, is $\mathrm{Si}(4008 \mathrm{mAh} / \mathrm{g}){ }_{1}^{[3]}$ though revealing major issues currently prevent market maturity. ${ }^{[4]}$ The drawbacks found are reactions with large volume change during alloying/dealloying with lithium resulting in pulverization of the Si particles, which leads to a degradation of the electrode integrity and therefore to a drastic capacity loss while cycling. ${ }^{[5]}$ Many different investigations on the improvement of the capacity retention were conducted, leading to the conclusion that nanosized and nanostructured $\mathrm{Si}$ is necessary to counteract the pulverization effects. ${ }^{[5-7]}$

Another issue hampering the implementation of pure $\mathrm{Si}$ anodes in applications is the comparatively low C-rate compatibility. ${ }^{[8]}$ Intercalation-based materials offer the possibility to provide very high specific current densities if needed, which is not possible for a $\mathrm{Si}$ anode because of the different reaction mechanism. ${ }^{[5]}$ Therefore, $\mathrm{Si}$ as anode material is an ideal candidate for low power applications with less necessity of a high reversibility. A growing area of such applications for low power electronics is the field of printed electronics (PE).

The research field of $P E$ deals with printing of electric circuits with cost-effective and up-scalable techniques. ${ }^{[9]}$ With this approach, the transition from Si-based circuits on rigid substrates towards flexible large-scale printed devices can be carried out. PE technology can be used to create variable patterns with suitable solution processed inks on the surface of any possible material, including flexible substrates, dielectrics, etc.. ${ }^{[10,11]}$ Active PE applications usually need a power source for independent operation. Different types of power sources have been considered, e.g., energy harvesting devices or batteries, sharing the need to be flexible and to provide the required power. ${ }^{[12]}$ Desirably, the lifetime of these power supply units should fit to the lifetime of the printed application and they should be reusable or disposable. In this scenario, flexible 
batteries with non-toxic active materials are attractive choices, e.g., $\mathrm{Si}$ as anode material due to its nontoxicity, its high theoretical specific capacity of $4008 \mathrm{mAh} / \mathrm{g}$ and its natural abundance. ${ }^{[13]}$

The present work investigates the suitability of Si anodes, including the influence of carbon coating, for usage in a printed battery to power specific printed applications. To achieve this goal, different Si nanoparticles (with and without carbon coating) were prepared, characterized, and afterwards implemented in a printable aqueous ink. Si anodes were printed, using a microplotting technique. Subsequently, the electrochemical characterization was performed. Finally, a full cell containing $\mathrm{NCM}\left(\mathrm{Li}\left(\mathrm{Ni}_{1 / 3} \mathrm{CO}_{1 / 3} \mathrm{Mn}_{1 / 3}\right) \mathrm{O}_{2}\right)$ as cathode and the printed $\mathrm{Si}$ as anode was assembled and tested on a printed transistor (battery used as source/gate potential to open the semiconducting channel) to ensure the direct applicability of the materials.

\section{Results and Discussion}

Two different Si compounds were used for ink preparation, Si nanoparticles (Si) and carbon-coated Si nanoparticles (Si/C). The carbon coating process was based on a pyrolysis reaction, using a decomposition of glucose as carbon source, as explained in the experimental section. Figure 1a presents the X-ray diffraction (XRD) pattern of $\mathrm{Si}$ and $\mathrm{Si} / \mathrm{C}$ (JCPDS no. 271402), which indicate that crystalline Si phases exist in both Si and $\mathrm{Si} / \mathrm{C}$ composites. ${ }^{[14]}$

The amount of carbon incorporated in the coating was determined by thermogravimetric analysis (TGA). Figure $1 \mathrm{~b}$ shows the thermogravimetrical analysis (TGA) data of $\mathrm{Si}$ and $\mathrm{Si}$ / $\mathrm{C}$ composites. The nanopowders were heated to $800^{\circ} \mathrm{C}$ in ambient air and the mass change detected. The mass decrease of $\mathrm{Si}$, around $200-300^{\circ} \mathrm{C}$, can be attributed to the decomposition of surface groups, which were formed during the industrial Si synthesis. The mass increase starting between 500 and $600{ }^{\circ} \mathrm{C}$ can be assigned to $\mathrm{SiO}_{x}$ formation in case of $\mathrm{Si}$ nanoparticles. ${ }^{[15]}$ Since this $\mathrm{SiO}_{x}$ formation appears in the case of $\mathrm{Si} / \mathrm{C}$ composites after decomposition of the carbon shell as well, the mass difference at $800^{\circ} \mathrm{C}$ between both measure- ments is related to the total amount of carbon burnt. The mass increase at a later stage of $\mathrm{Si}$ and $\mathrm{Si} / \mathrm{C}$ nanopowders can be ascribed to the formation of $\mathrm{SiO}_{2}$ due to oxidation of silicon. The TGA measurement comparison of both nanopowders results in a carbon content of $\sim 10 \mathrm{wt} \%$, which is in good agreement with performed elemental analysis and XPS measurements (see Figure S1a,b and Figure 2c).

Raman Spectroscopy was used to identify the structure of the carbon coating, by measuring the characteristic defect band spectrum of the carbonaceous coating material based on the vibrational modes. ${ }^{[16]}$ The Raman spectrum of Si/C (Figure 1c) exhibits two distinctive peaks at $1350 \mathrm{~cm}^{-1}$ and $1595 \mathrm{~cm}^{-1}$, corresponding to the $D$ and $G$ bands, respectively. ${ }^{[16]}$ The intensity ratio of the $D$ band to $G$ band $\left(I_{D} / I_{G}\right)$ was calculated to be 0.67 (as given in Figure S2), therefore, the carbon layer can be presumed to be a mixture of nanocrystalline graphite and amorphous carbon with a low $\mathrm{sp}^{3} / \mathrm{sp}^{2}$ hybridization ratio. ${ }^{[17]}$ The two typical peaks of Si at $520 \mathrm{~cm}^{-1}$ and $\mathrm{SiO}_{2}$ at $1000 \mathrm{~cm}^{-1}$ (indicated in Figure 1c) could be detected in both samples.

Transmission electron microscopy (TEM) and scanning electron microscopy (SEM) measurements were performed to gain further insights into the structure of the $\mathrm{Si}$ and the $\mathrm{Si} / \mathrm{C}$ nanoparticles (for SEM, refer Figure S3). Figure 2a shows a high resolution TEM (HR-TEM) micrograph of Si nanoparticles, along with a magnified image denoting the clear lattice fringes of $\sim 0.32 \mathrm{~nm}$, corresponding to the Si (111) plane. The selected area electron diffraction (SAED) pattern is displayed as inset of the image to confirm the crystallinity of the Si observed by XRD. TEM micrographs of Si nanoparticles show particle sizes of $\sim 50 \mathrm{~nm}$ and exhibit a thin $(\sim 10 \mathrm{~nm}) \mathrm{SiO}_{2}$ shell (see Figure S4a). Figure $2 \mathrm{~b}$ shows similar findings for the $\mathrm{Si} / \mathrm{C}$ compound. Lattice fringes of around $0.32 \mathrm{~nm}$ and Si nanoparticles with $\sim 50 \mathrm{~nm}$ diameter (Figure S4b) could be found. Additionally, a carbon shell could be detected, as further displayed in Figure 2c. Here, for the Si/C compound, STEM-EDS mapping (energy dispersive $\mathrm{X}$-ray spectroscopy) was utilized to confirm the presence of the coated carbon layer (few nanometers). The elemental composition mapping results of $\mathrm{Si}$ and $\mathrm{C}$ along with its representative STEM image are displayed, the results are in accordance with
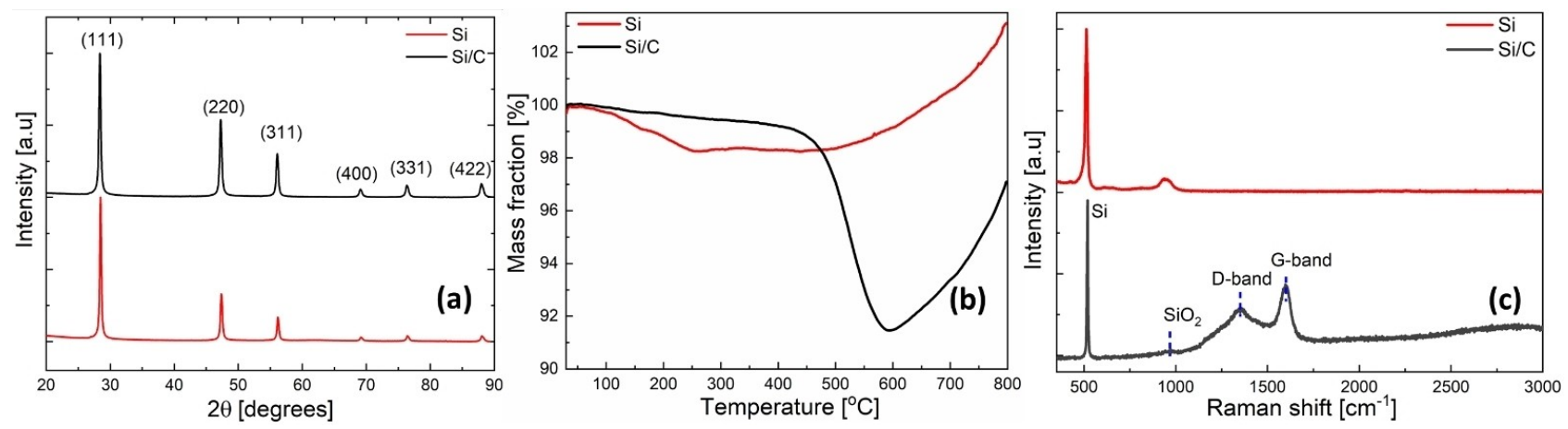

Figure 1. a) XRD patterns of $\mathrm{Si}$ and $\mathrm{Si} / \mathrm{C}$ show crystalline Si (JCPDS no. 27-1402), b) thermogravimetrical measurements of Si/C reveal a carbon content of ca. $10 \mathrm{wt} \%, \mathrm{c})$ Raman spectra of the $\mathrm{Si}$ and $\mathrm{Si} / \mathrm{C}$ indicate the presence of carbon coating in the latter case. 

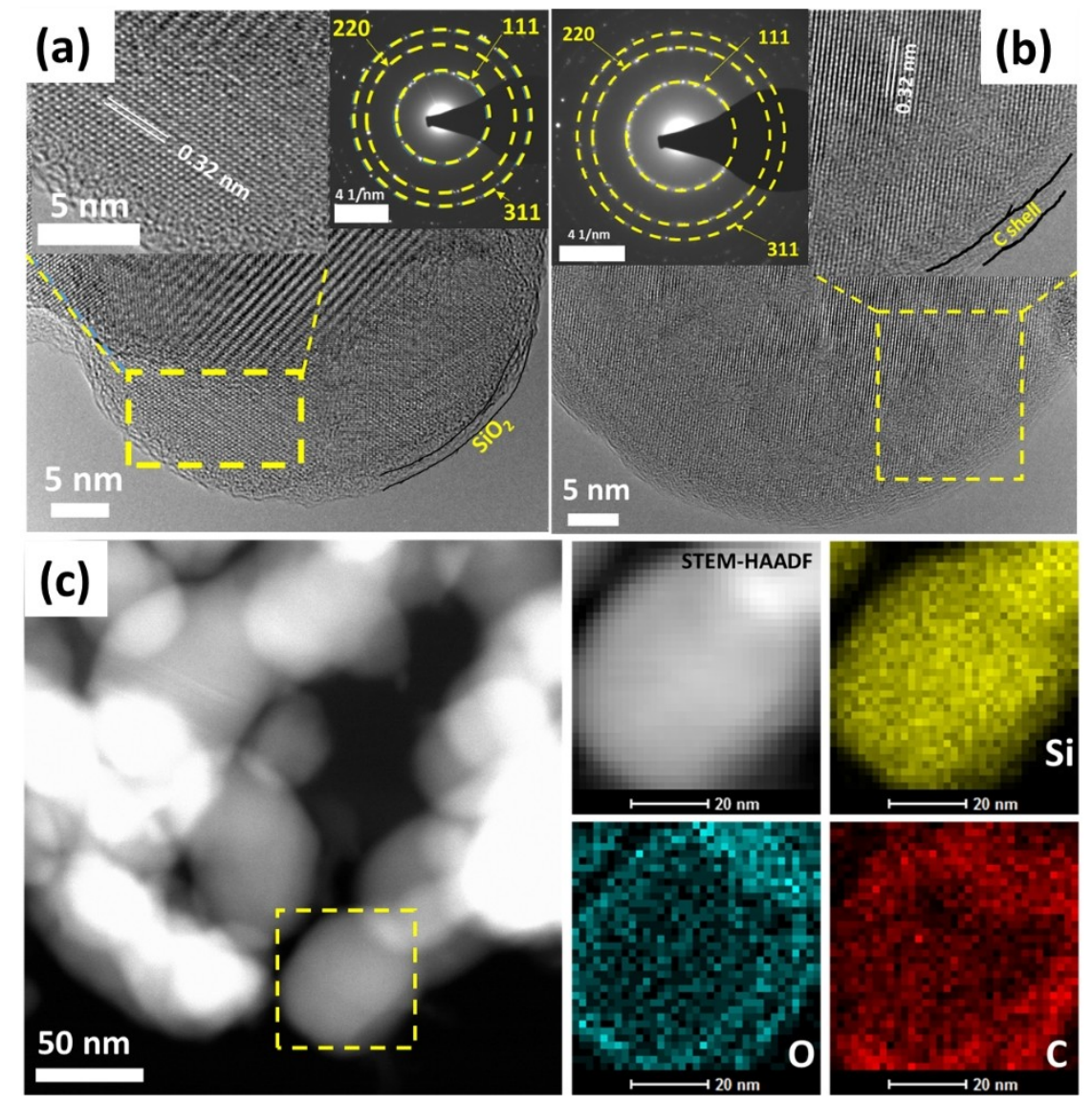

Figure 2. HR-TEM micrographs of a) pristine $\mathrm{Si}$, b) $\mathrm{Si} / \mathrm{C}$ nanoparticles possessing an amorphous non continuous carbon shell. SAED patterns of both samples confirm the crystallinity of Si and Si/C nanoparticles. c) STEM-EDS elemental mapping of a Si/C nanoparticle.

the outcome of the XPS measurements shown in Figure S1a and $b$.

The tailoring of the carbon coating on Si was conducted for two reasons. Literature reports reveal the enhanced electrochemical performance of carbon-coated Si and the printability of the prepared ink for ink-jet printing is increased. ${ }^{[6,14,18]}$ The printability of an ink is usually connected to different material properties and ink fluidity behaviour as well as on the chosen printing procedure. Two inks were prepared using $\mathrm{Si}$ or $\mathrm{Si} / \mathrm{C}$ as active materials, polyvinyl alcohol (PVA) as binder and conductive carbon (C65) as additive to render the slurry conductive. Depending on the agglomeration and segregation of particles and the viscosity of the ink, the adhesion properties on the current collector surface and the printability of the ink change. The pure Si ink showed severe segregation and agglomeration of $\mathrm{Si}$, leading to clogged printing nozzles and impeding the storage and reuse of the ink. The particle size distribution and the agglomeration behaviour over time was investigated using dynamic light scattering (DLS). A visible colour difference of the two inks directly after preparation was observable and is demonstrated in Figure $3 a$, the size distribution of the nanoparticles with respect to residence time in water are depicted in Figure 3b (concentration of both dispersions was kept constant at $40 \mathrm{mg} / \mathrm{L}$ ). The $\mathrm{Si}$ particles were found to form large agglomerates, with a maximum around $520-540 \mathrm{~nm}$ and precipitating faster than the $\mathrm{Si} / \mathrm{C}$ compound. The $\mathrm{Si} / \mathrm{C}$ compound can be easily dispersed in water without forming large fractions of bigger agglomerates. Here, the major volume fraction is represented by aggregates with diameters between 290-320 nm. Possibly, the increased amount of polar groups attached to the carbon shell (resulting from the pyrolysis process of glucose) leads to a higher hydrophilic character compared to pure $\mathrm{Si}$, and therefore to a better dispersivity in polar solvents

\subsection{Electrochemical Characterization}

To examine the effect of carbon coating on the electrochemical performance of $\mathrm{Si}$ anodes, a comparative study between $\mathrm{Si}$ and $\mathrm{Si} / \mathrm{C}$ electrodes was conducted. Both $\mathrm{Si}$ and $\mathrm{Si} / \mathrm{C}$ inks were printed, using a micro-plotting technique, and the electrochemical performance compared. The printing process allows precise deposition of the slurry, so that electrodes with the same loading $\left(\sim 0.3 \mathrm{mg}_{\mathrm{si}} / \mathrm{cm}^{2}\right)$ could be compared. Additionally, cross section SEM micrographs (Figure S5) were taken from printed $\mathrm{Si}$ and $\mathrm{Si} / \mathrm{C}$ electrodes. A homogenous distribution of the nanoparticles and a presence of smooth interfaces between substrate and the printed thin films could be found. The printed electrodes were tested in coin-type cells, using $1 \mathrm{M}$ 

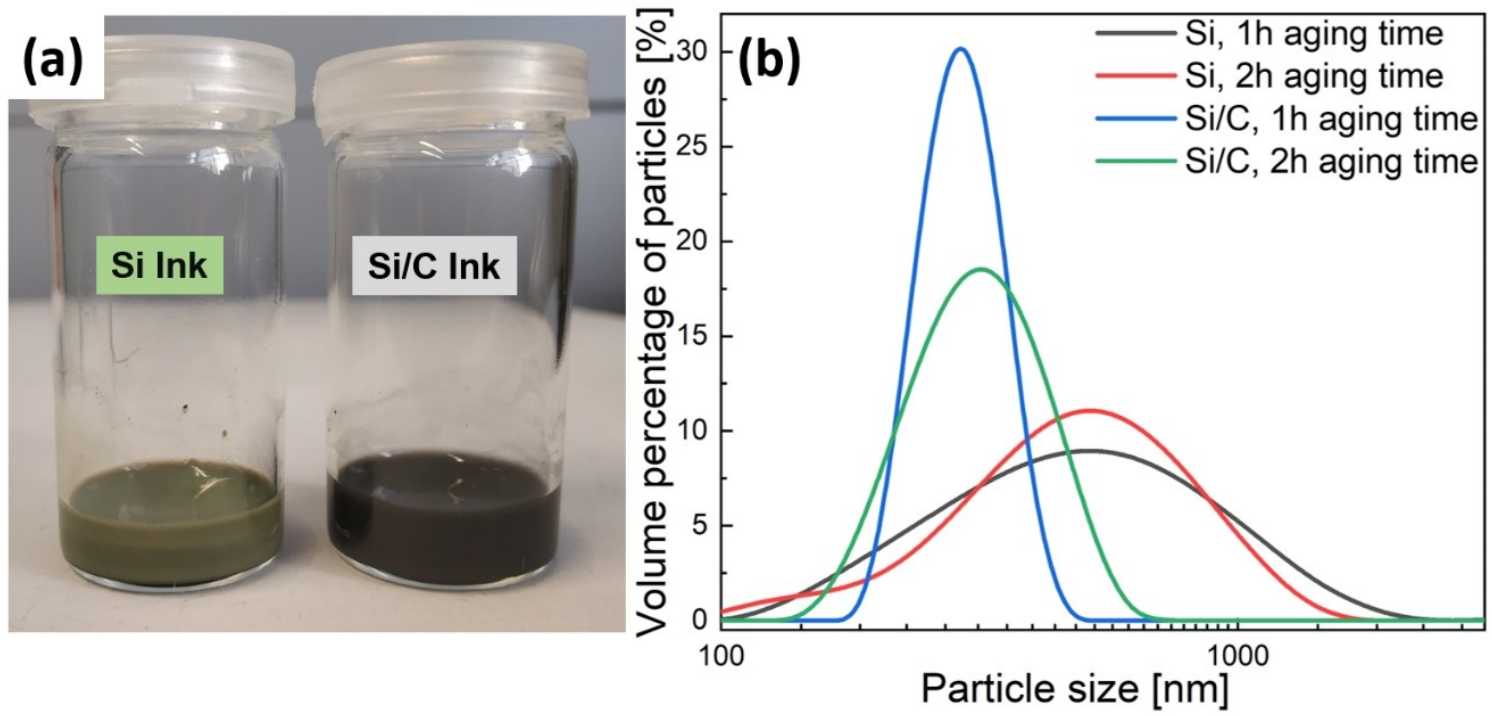

Figure 3. a) Photograph showing a visible color difference of the inks and b) DLS studies of the aggregation of the Si and Si/C composite ink dispersion with respect to time.

$\mathrm{LiPF}_{6}$ with FEC/EMC (1:1 wt\%) as electrolyte and lithium foil as counter electrode. Cycling was performed using cut-off potentials of $10 \mathrm{mV}$ and $1 \mathrm{~V}$ at different C-rates (where $1 \mathrm{C}=$ $4000 \mathrm{~mA} / \mathrm{g}_{\mathrm{si}}$ ) with included constant voltage step with a $\mathrm{C} / 10$ cut-off current. Figure 4 shows the comparative electrochemical characterization of the $\mathrm{Si}$ and the $\mathrm{Si} / \mathrm{C}$ composite materials.

Figure 4a shows galvanostatic testing using different specific current densities (with constant voltage holding step as described in Table S1). The specific capacities are calculated based on the weight of active material (Si). Over the first 20 cycles the specific current densities are set to $0.2 \mathrm{~A} / \mathrm{g}, 0.4 \mathrm{~A} / \mathrm{g}$, $0.8 \mathrm{~A} / \mathrm{g}, 2 \mathrm{~A} / \mathrm{g}, 4 \mathrm{~A} / \mathrm{g}$ and $2 \mathrm{~A} / \mathrm{g}$, respectively. The initial discharge capacities for $\mathrm{Si}$ and $\mathrm{Si} / \mathrm{C}$ amount to 4135 and $4240 \mathrm{mAh} / \mathrm{g}_{\mathrm{si}}$. The high first discharge capacities (above the theoretical value) can be attributed to irreversible reactions deriving from reductions of the functional groups at the carbon coating or the silicon surface. While the Si electrode shows a decay of the capacity over the first 100 cycles and a strong impact of the C-rate, the $\mathrm{Si} / \mathrm{C}$ electrodes do show much less capacity degradation and a better electrochemical performance at higher $\mathrm{C}$-rates. The capacity of the $\mathrm{Si}$ decayed after 100 cycles at $2 \mathrm{~A} / \mathrm{g}$ to $800 \mathrm{mAh} / \mathrm{g}_{\mathrm{si}}$, while the $\mathrm{Si} / \mathrm{C}$ showed a greatly enhanced capacity retention, with $1754 \mathrm{mAh} / \mathrm{g}_{\mathrm{si}}$ after 100 cycles using the same specific current density values. Additionally, the coulombic efficiency for the Si/C electrodes is stabilized compared to the $\mathrm{Si}$ electrodes. Figure $4 \mathrm{~b}$ shows the typical discharge/charge profiles of the $1^{\text {st }}$ and $100^{\text {th }}$ cycle for the two types of electrodes. These results indicate an improved electrochemical performance of the $\mathrm{Si} / \mathrm{C}$ electrodes compared to $\mathrm{Si}$. This improved performance can be ascribed to the conductive carbon coating resulting in a higher specific capacity and cycling stability of the electrode. ${ }^{[14,19]}$ The areal capacities of the $\mathrm{Si}$ and $\mathrm{Si} / \mathrm{C}$ electrodes amount to $0.5 \mathrm{mAh} / \mathrm{cm}^{2}$ and $0.65 \mathrm{mAh} /$ $\mathrm{cm}^{2}$ at the 17 th cycle (first cycle in the long-term cycling at $2 \mathrm{~A} /$ (a)

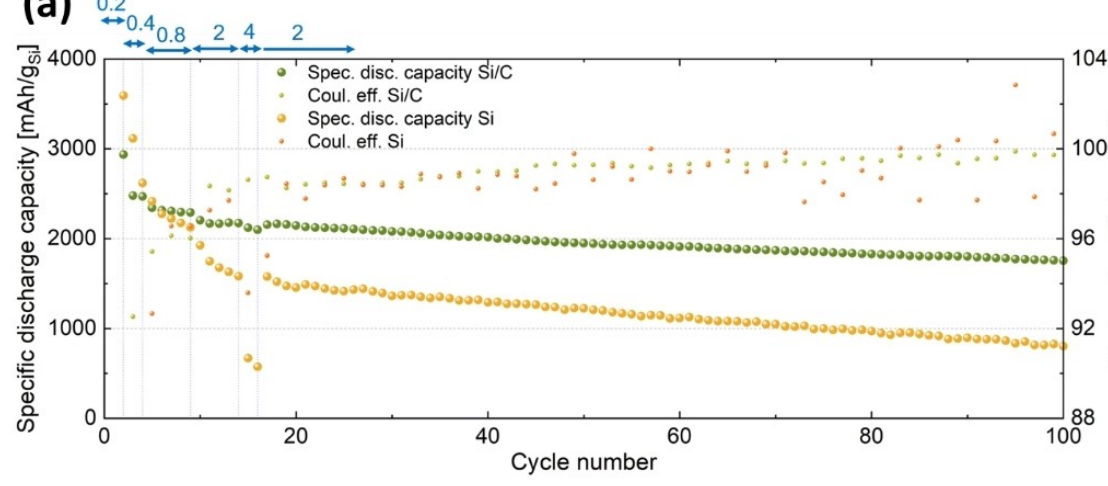

(b)

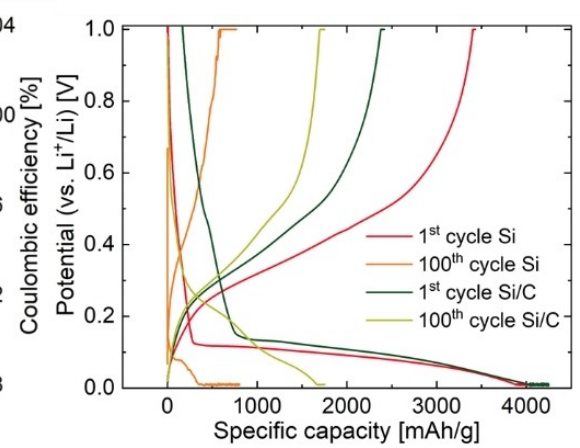

Figure 4. a) Galvanostatic cycling performance of printed Si electrode cycled at various current rates versus cycle number. The current steps are implemented during the first 20 cycles and amount to $0.2 \mathrm{~A} / \mathrm{g}, 0.4 \mathrm{~A} / \mathrm{g}, 0.8 \mathrm{~A} / \mathrm{g}, 2 \mathrm{~A} / \mathrm{g}, 4 \mathrm{~A} / \mathrm{g}$ and $2 \mathrm{~A} / \mathrm{g}$, respectively. b) $1^{\text {st }}$ and $100^{\text {th }}$ charge/discharge profiles of Si and Si/C electrodes respectively. The testing protocol is explained in detail in Table S1. The current densities in a) are given in units of $\mathrm{A} / \mathrm{g}$. 
g), respectively. Furthermore, the electrochemical performances of both electrodes at different current densities are presented in Table 1.

\subsection{Electrochemical Impedance Analysis of Symmetric Cells}

The conductivity properties of the $\mathrm{Si} / \mathrm{C}$ and the $\mathrm{Si}$ electrodes were analysed using electrochemical alternating current impe-

\begin{tabular}{|c|c|c|c|}
\hline $\begin{array}{l}\text { Cycle } \\
\text { number }\end{array}$ & $\begin{array}{l}\text { Current density } \\
{[\mathrm{A} / \mathrm{g}]}\end{array}$ & $\begin{array}{l}\text { Discharge capacity } \\
\text { Si electrode } \\
{\left[\mathrm{mAh} / \mathrm{g}_{\mathrm{si}}\right]}\end{array}$ & $\begin{array}{l}\text { Discharge capacity } \\
\mathrm{Si} / \mathrm{C} \text { electrode } \\
{\left[\mathrm{mAh} / \mathrm{g}_{\mathrm{si}}\right]}\end{array}$ \\
\hline 2 & 0.2 & 3592 & 2937 \\
\hline 4 & 0.4 & 2619 & 2471 \\
\hline 9 & 0.8 & 2125 & 2292 \\
\hline 14 & 2 & 1583 & 2174 \\
\hline 16 & 4 & 574 & 2099 \\
\hline 100 & 2 & 803 & 1753 \\
\hline
\end{tabular}

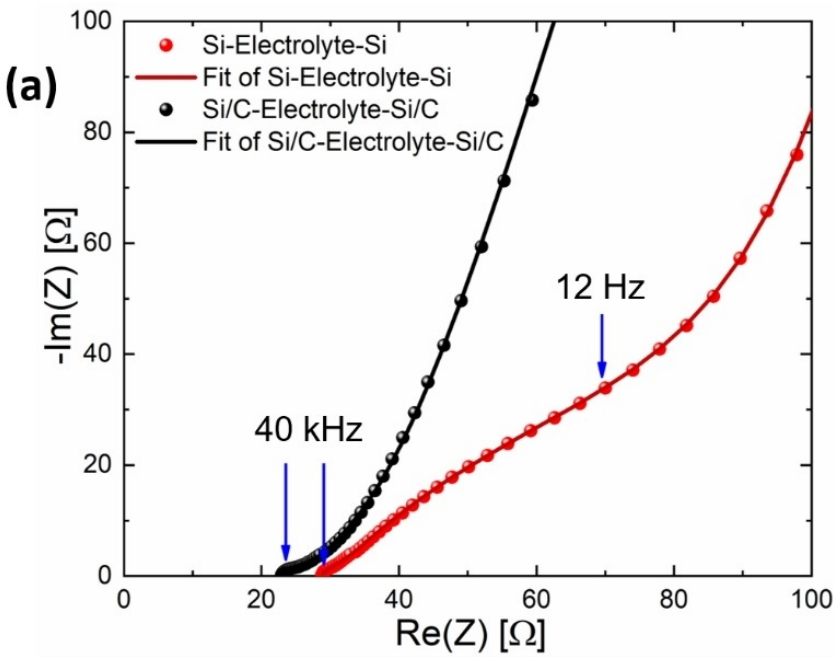

(c)

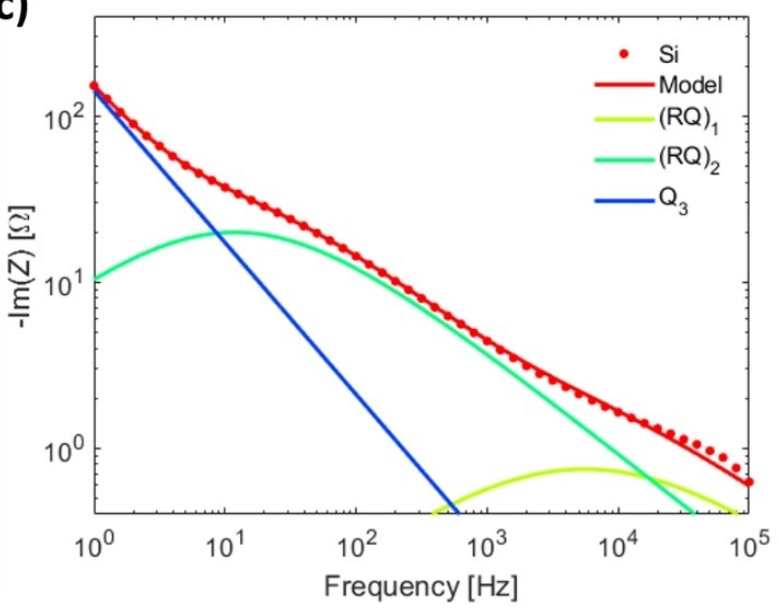

dance spectroscopy (EIS). In order to identify the individual processes contributing to the EIS response, two-electrode cells in symmetric cell configuration (either two printed Si electrodes or two printed $\mathrm{Si} / \mathrm{C}$ electrodes) were fabricated and measured. The electrolyte composition for both cells was $1 \mathrm{M} \mathrm{LiPF}_{6}$ salt in FEC: EMC solution. Figure 5a shows the Nyquist plot of the two symmetric cells. The experimental spectra of both electrodes (denoted by symbols) are dominated by a low-frequency blocking feature and further consist of two flattened higherfrequency semicircles and a high-frequency $Z_{\text {real }}$-intercept. ${ }^{[20,21]}$

In order to get a further insight into the EIS features, the data were fitted using the equivalent circuit shown in Figure 5b, using the Zview software (Scribner Associates, Southern Pines, NC). This equivalent circuit comprises of a series connection of a contact resistance $\left(R_{5}\right)$, two resistor $(R)$-constant phase elements (CPE) in parallel $\left(R_{1}, R_{2}\right.$ with $\left.Q_{1}, Q_{2}\right)$, and a series constant phase element $\left(Q_{3}\right) .^{[22,23]}$ The fits are added as solid lines to Figure $5 \mathrm{a}$, showing very good agreement with the experiments. The high-frequency resistance values $\left(R_{s}\right)$ of the $\mathrm{Si} / \mathrm{C}$ and $\mathrm{Si}$ electrodes were found to be $22.6 \Omega$ and $28.5 \Omega$,

(b)
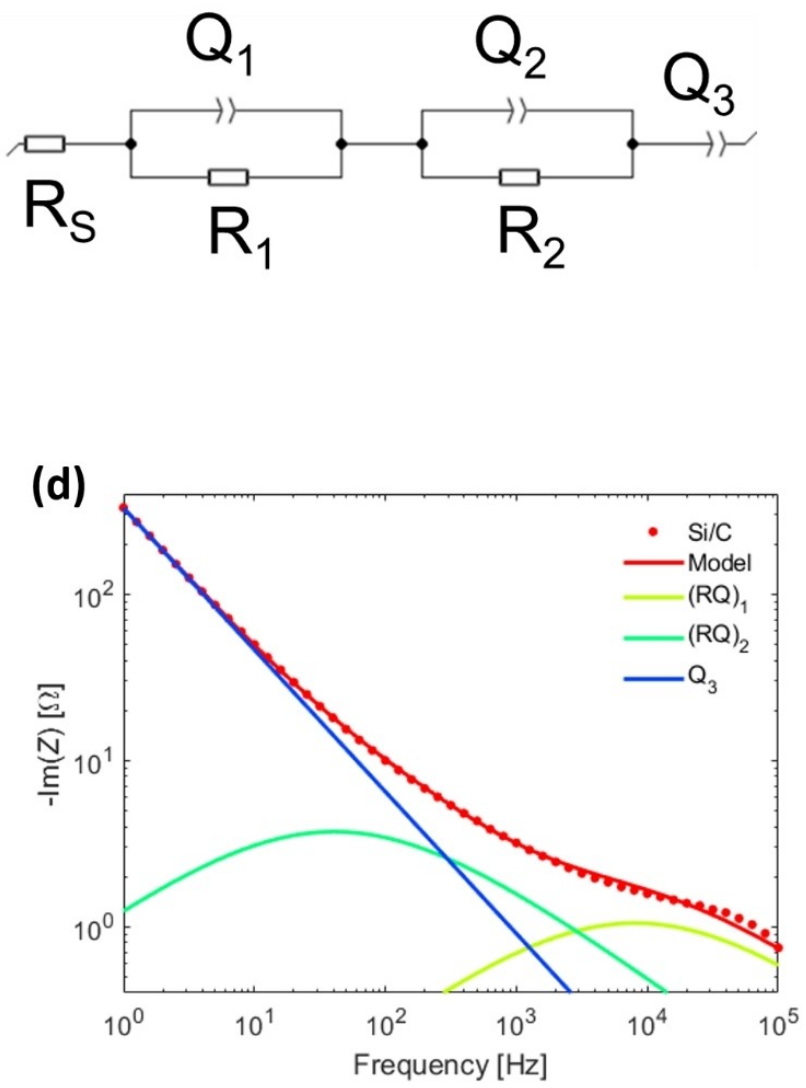

Figure 5. a) Electrochemical impedance spectra of symmetrical cells with $\mathrm{Si}$ and $\mathrm{Si} / \mathrm{C}$ electrodes along with fitted curves in a frequency range of $1 \mathrm{MHz}-1 \mathrm{~Hz}$ (fitting performed with Zview), b) equivalent circuit for fitting the experimental data (where $R_{5}, R_{1}, R_{2}$ denote the resistances, $Q_{1}, Q_{2}, Q_{3}$ designate constant phase elements), c) and d) deconvolution of the imaginary part into the three equivalent subcircuits $(R Q)_{1},(R Q)_{2}$ and $Q_{3}$. A Bode plot of the same data is shown in Figure $\mathrm{S} 6$. 
respectively. They can be attributed to the ohmic resistance of the electrolyte and the current collection system. The lower value of the $\mathrm{Si} / \mathrm{C}$ electrode may be due to better electronic contact of the electrode with the current collectors resulting from the presence of carbon.

Figure $5 c$ and $d$ show a deconvolution of the imaginary part of the impedance of the $\mathrm{Si}$ and $\mathrm{Si} / \mathrm{C}$ cells, respectively, into the circuit subcomponents, allowing to visualize their individual contributions. Both spectra show two $R Q$-features, a small one at ca. $40 \mathrm{kHz}$ and a larger one at ca. $12 \mathrm{~Hz}$, as well as a dominating $Q$ feature. The latter can be assigned to the blocking nature of the electrodes (note that none of the electrodes was pre-lithiated, so a large resistance towards delithiation is expected). We tentatively assign the larger of the two $R Q$ features, $(R Q)_{2}$, to charge transfer. The charge-transfer resistances of $\mathrm{Si} / \mathrm{C}$ electrodes $\left(R_{2}\right)$ were found to be approximately $15.4 \Omega$, which is much lower than these of Si electrodes $(74.9 \Omega)$. The lower value of $\mathrm{Si} / \mathrm{C}$ electrodes may be obliged to a wide network of conductive carbon, resulting from the carbon coating. The origin of the high-frequency feature $(R Q)_{1}$, which is much smaller, is unclear.

In conclusion, due to the presence of carbon coating, the EIS analyses indicate that $\mathrm{Si} / \mathrm{C}$ electrodes exhibit enhanced electrical conductivities and improved charge-transfer kinetics. For the interested reader, a supplementing Bode plot is depicted in Figure S6. The fitted parameter values of the equivalent circuit are summarized in Table S2.

\subsection{Printed Si/C Anodes for Printed Electronic Applications}

To demonstrate the applicability of the printed battery electrode for printed electronic devices, a full cell in coin-type cell geometry was constructed. As testing device an electrolyte gated ink-jet printed transistor was chosen to analyse the battery/transistor compatibility, for printing the electrolytegated transistor, a technique reported by Singaraju et al. was adapted. ${ }^{[24]} \mathrm{A}$ unique feature of the electrolyte gated transistors is the possibility to operate at low voltages, enabling a direct potential supply from a battery without power converter. The printed graphene transistor was prepared by inkjet printing indium oxide $\left(\mathrm{In}_{2} \mathrm{O}_{3}\right)$ semiconductor precursor ink on a clean glass substrate. The substrate and the printed layer were annealed to form a uniform oxide film and subsequently passive graphene electrodes (source and drain) were printed on both sides of the semiconductor and a gate electrode in inplane geometry ${ }^{[24]}$ (Figure 6a and b). As gating material, a composite solid polymer electrolyte (in detail described in) ${ }^{[24]}$ was inkjet-printed across the semiconductor and gate electrode. ${ }^{[1,25]}$ The semiconductor channel length, width and thickness were $50 \mu \mathrm{m}, 60 \mu \mathrm{m}$ and $200 \mathrm{~nm}$, respectively. Figure $6 a$ and $b$ depict a schematic view and an optical image of the printed graphene transistor used for this study. The prepared cell utilized $\mathrm{NCM}\left(\mathrm{LiNi}_{1 / 3} \mathrm{Co}_{1 / 3} \mathrm{Mn}_{1 / 3} \mathrm{O}_{2}\right)$ as cathode material and the printed $\mathrm{Si} / \mathrm{C}$ as anode, the battery construction followed the above described half-cell arrangements (cyclic voltammetry of the full-cell is demonstrated in Figure S7). Before the full-cell was attached to the printed transistor, the cell was charged to $3 \mathrm{~V}$ (vs. $\mathrm{Li}^{+} / \mathrm{Li}$ ) and afterwards directly

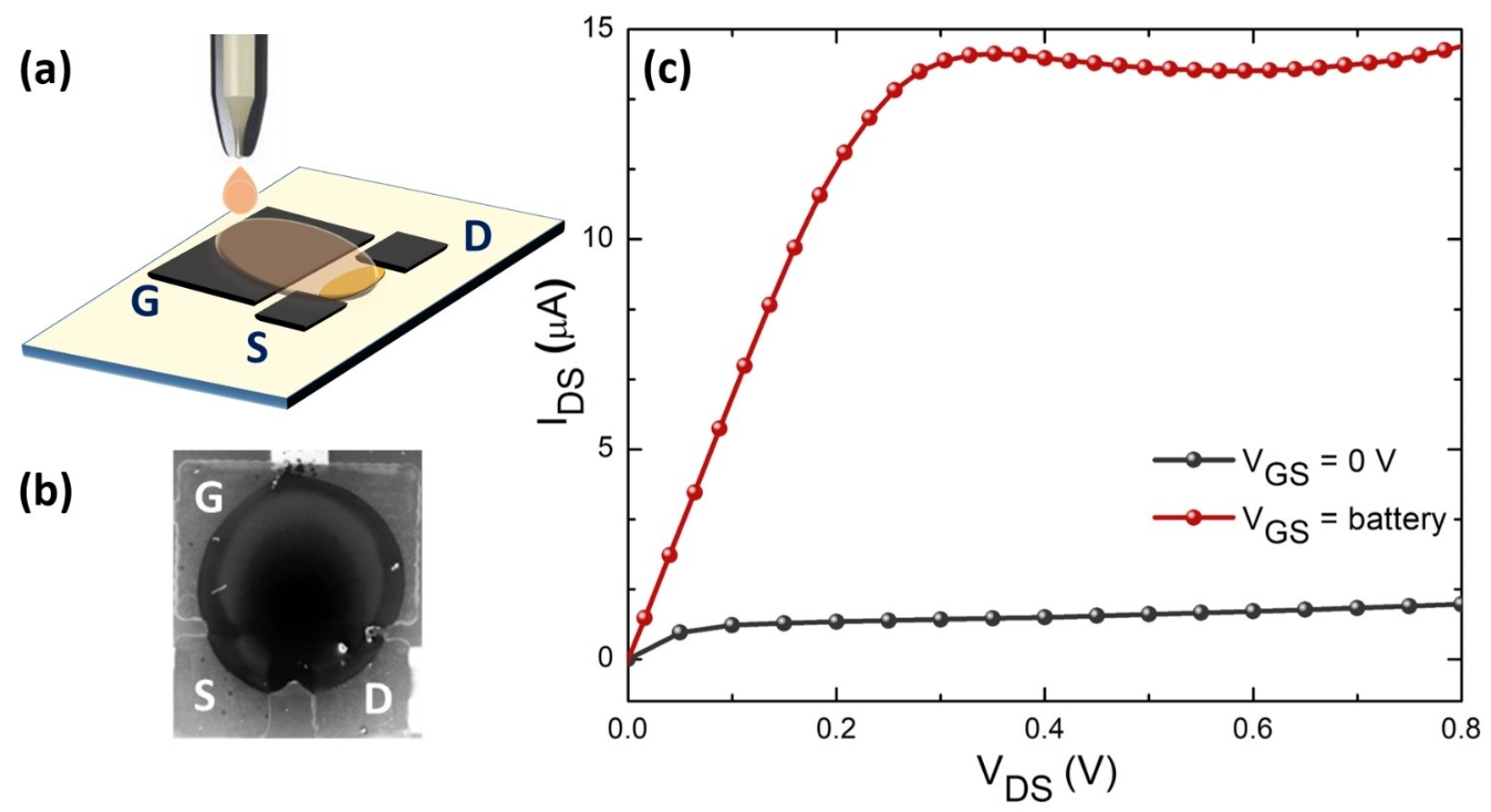

Figure 6. a) Schematic view of printed graphene transistor, b) optical microscope image of the printed transistor with gate (G), source (S), drain (D) terminals and c) electrical characterization of transistor powered with and without battery at the gate terminal. 
connected to provide the necessary gate potential $\left(V_{G}\right)$ for transistor operation.

Figure $6 \mathrm{c}$ illustrates the output curves of the single printed transistor with the printed battery connected to supply the gating potential (OCV of the cell after connection to the transistor: $\mathrm{OCV}=V_{\mathrm{G}}=2.1 \mathrm{~V}$, slightly changing over operation) and without any gate potential $\left(V_{G}=0\right)$. It can be seen that the battery is capable of switching a printed transistor on and off for more than 10 minutes, therefore indicating that printed electronic circuits can be successfully powered by printed $\mathrm{Si} /$ $\mathrm{NCM}$ batteries with loadings in the low $\mathrm{mg} / \mathrm{cm}^{2}$ range and without requiring a power converter.

\section{Conclusions}

Printed $\mathrm{Si}$ anodes could be characterized and optimized regarding printability and capacity. Therefore, a partial carbon coating was used to decrease particle agglomeration in the ink and to simultaneously enhance the electrochemical performance. Specific capacities around $1754 \mathrm{mAh} / \mathrm{g}_{\mathrm{si}}$ could be shown for printed Si/C anodes after 100 cycles, with C-rates up to $1 \mathrm{C}$. In order to show the compatibility of the printed $\mathrm{Si} / \mathrm{C}$ anodes with printed electric circuits, a full cell, using a printed Si/C anode and commercially available NCM as cathode, was constructed, and a printed transistor successfully switched on and off. This demonstrates that printed $\mathrm{Si} / \mathrm{C}$ anodes can be used directly without power converter for electrolyte-gated transistors and that this paves the way for $\mathrm{Si} / \mathrm{C}$ anode utilization in future printed applications.

\section{Experimental Section}

\section{Sample and electrode preparation}

In a typical experiment, $0.5 \mathrm{~g}$ of $\mathrm{Si}$ nanoparticles (99.95\%; Alfa Aesar) were dispersed in $50 \mathrm{~mL}$ of ethanol ( $99.5 \%$; Sigma Aldrich). After stirring the suspension, additional $0.25 \mathrm{~g}$ of glucose $(99.9 \%$; Sigma Aldrich), dissolved in $10 \mathrm{~mL}$ of deionized water were added. Afterwards the solution was stirred at $90^{\circ} \mathrm{C}$ for $2 \mathrm{~h}$. After solvent evaporation, the particles were calcined in $\mathrm{Ar} / \mathrm{H}_{2}$ atmosphere at $600^{\circ} \mathrm{C}$ for $4 \mathrm{~h}$. The $\mathrm{Si} / \mathrm{C}$ composite was used without further treatment for electrode preparation. The electrode slurry was prepared via thorough mixing of $\mathrm{Si}$ or $\mathrm{Si} / \mathrm{C}$ composite nanoparticles (63 wt.\%), C65 (22 wt.\%; Timical USA) and PVA (polyvinyl alcohol, 15 wt.\%; Solvay 425) by using a high energy dispersion Thinky mixer (ARE 500, Japan). The composition ratio of active material, carbon addictive and binder were adapted based on the previous works stated by C. Erk et al. ${ }^{[26]}$ and I. Kovalenko et al... ${ }^{[27]}$ The asprepared slurry was printed on Cu foils (MTI Corp., USA) by using a robotic dispensing system (Sonoplot Microplotter II, USA). The utilized Sonoplot Microplotting system makes use of a glass capillary, which was in our case filled with the $\mathrm{Si}$ or Si/C based inks. During printing, a vibration of the capillary can be applied, deriving from a piezo-element. A resonance vibration was applied to the piezo electric in order to achieve the best printing results. The capillaries with a tip diameter $\sim 400 \mu \mathrm{m}$ were used for microplotting. The resonant dispensing frequency and voltage of $424 \mathrm{kHz}$ and $20 \mathrm{~V}$ were employed, respectively. Square patterns with $9 \mathrm{~mm}$ were printed on a copper metal foil of $13 \mathrm{~mm}$ diameter.
Later, these printed electrodes were dried in a vacuum oven at $80^{\circ} \mathrm{C}$ overnight inside an $\mathrm{Ar}$-filled glove box $\left(\mathrm{O}_{2}\right.$ and $\left.\mathrm{Ar}<0.5 \mathrm{ppm}\right)$ under reduced pressure. For cathode preparation, NCM 111 (BASF SE, Ludwigshafen), C65 and PVDF (Solef 5130, Solvay) were mixed in $8: 1: 1$ ratio with adequate amount of NMP (N-methyl-2pyrrolidone, Sigma Aldrich).The prepared electrode slurries were tape casted by using $200 \mu \mathrm{m}$ doctor blade on Al foil (Gelon LIB Co., Ltd, China) and electrode sheets were dried overnight at $80^{\circ} \mathrm{C}$ under reduced pressure. The cathode active material loading was fixed at $1.5 \mathrm{mg} / \mathrm{cm}^{2}$. Electrode disc dimensions of $13 \mathrm{~mm}$ were fixed for both cathode and anode samples. For full-cell preparation, printed anode electrode was prepared by mixing $\mathrm{Si} / \mathrm{C}$ nanoparticles (50 wt $\%$ ), C65 (40 wt\%) and PVA (10 wt $\%$ in water) and tape-casted NCM as cathode.

\section{Structural Characterization}

X-ray diffraction (XRD) was conducted using Bruker D8 Advance diffractometer with a $\mathrm{Cu}-\mathrm{K} \alpha$ radiation source and equipped with a LYNXEYE detector of fixed divergence slit $\left(0.3^{\circ}\right)$. SEM characterization was performed using Leo 1530 scanning electron microscope. Transmission electron microscopy measurements were conducted on powder samples dispersed on a gold grid. TEM and STEM-EDS analysis of the nanoparticles was carried out with an image-Cs corrected Titan 80-300 (FEI) operated at acceleration voltage of $300 \mathrm{kV}$. XPS measurements of Si/C nanoparticles were conducted using Specs Phoibos 150 electron spectrometer equipped with Al Ka X-ray radiation source. XPS sample scans were performed on the Si/C nanoparticles with spot size of $1 \mathrm{~mm}$. Si and $\mathrm{Si} / \mathrm{C}$ nanoparticles were measured in aqueous suspension by dynamic light scattering (DLS-Nano Zetasizer, Malvern Instruments, UK). Thermogravimetric analyses of as received $\mathrm{Si}$ and $\mathrm{Si} / \mathrm{C}$ composite samples were measured on a Netsch TG 209 F1 Libra instrument. Raman spectroscopy was performed with confocal Raman instrument (Renishaw, Wire 4.0, excitation wavelength $532 \mathrm{~nm}$, exposure time $30 \mathrm{~s}$ ) using the 10x magnifier lens. The spot size of the laser beam was $\sim 1 \mu \mathrm{m}$ and the spectra were taken in the range of $100-3000 \mathrm{~cm}^{-1}$. By deconvoluting the Raman spectra peaks in Wire 4.0 software with two Gaussian wave peaks, the carbon defect band intensities and peak positions were analysed.

\section{Electrochemical Characterization}

Viscosity of the slurry was adjusted for printability with microplotter by varying the solvent content. After drying the printed samples at $80^{\circ} \mathrm{C}$ at vacuum, coin type cells (using $13 \mathrm{~mm}$ circular electrodes) were assembled in an Ar filled glovebox $\left(\mathrm{O}_{2}\right.$ and $\mathrm{Ar}$ level below $0.5 \mathrm{ppm})$, with Li foil $(0.3 \mathrm{~mm}$ thick, Gelon LIB Co., Ltd, China) as counter electrode. $1 \mathrm{M} \mathrm{LiPF}_{6}$ in a $1: 1(\mathrm{w} / \mathrm{w})$ mixture of fluoroethylene carbonate (FEC) and ethyl methyl carbonate (EMC) was used as electrolyte. Glass microfiber filter paper (type GF/C, Whatman) was used as a separator. Electrochemical measurements were performed using an Arbin 2000 battery cycler. Electrochemical impedance spectroscopy measurements were carried out using a BioLogic VSP-300 potentiostat device. Impedance spectra were acquired by applying $50 \mathrm{mV}$ amplitude signal over a frequency range of $1 \mathrm{MHz}$ to $1 \mathrm{~Hz}$ (10 points/decade). For the construction of anode symmetric cell, two printed electrodes (Si or $\mathrm{Si} / \mathrm{C}$ ) were placed towards each other separated by two sheets of glass fibre separator. The electrolyte solution was poured to fill the space between the electrodes to complete an anode symmetric cell. All the electrochemical tests were carried out at room temperature. Current-rate (C-rate) was calculated for both electrodes as the product of active material loading of absolute Si content (in grams) and theoretical capacity of $\mathrm{Si}$ (in $\mathrm{mAh} / \mathrm{g}$ ). 


\section{Printed transistor characterization}

The electrical measurements (two-probe output characteristics) were measured using precision probe station (SUSS MicroTec MLC$150 C$ ) with a semiconductor parameter analyser (Agilent 4156C). For operation, the gate voltage was fixed at the battery voltage (full cell $\mathrm{Si} / \mathrm{C}$ anode/NCM cathode) and the drain voltage swept from $0 \mathrm{~V}$ to $1 \mathrm{~V}$. The source terminal was kept as common ground.

\section{Acknowledgements}

P.A.S. and S.A.S. acknowledge the Ministry of Science, Research and Arts of the State of Baden Württemberg for funding research through the MERAGEM graduate school fellowship. Authors thank Dr. Timo Barsch, David Kitsche for TGA measurements and Dr. Molina Jiron de Moreno Concepcion del Carmen for XPS analysis. B.B. and H.H. appreciate the support of EnABLES, a project funded by the European Union's Horizon 2020 research and innovation program under grant agreement no. 730957.

\section{Conflict of Interest}

The authors declare no conflict of interest.

Keywords: printing $\cdot$ silicon anode $\cdot$ carbon coating $\cdot$ lithiumion battery $\cdot$ rechargeable battery $\cdot$ printed electronics

[1] N. Nitta, F. Wu, J. T. Lee, G. Yushin, Mater. Today 2015, 18, 252.

[2] J. Cabana, L. Monconduit, D. Larcher, M. R. Palacín, Adv. Mater. 2010, 22, 170.

[3] C. K. Chan, H. Peng, G. Liu, K. Mcllwrath, X. F. Zhang, R. A. Huggins, Y. Cui, Nat. Nanotechnol. 2008, 3, 31.

[4] A. Schiele, B. Breitung, T. Hatsukade, B. B. Berkes, P. Hartmann, J. Janek, T. Brezesinski, ACS Energy Lett. 2017, 2, 2228.

[5] K. Feng, M. Li, W. Liu, A. G. Kashkooli, X. Xiao, M. Cai, Z. Chen, Small 2018, 14, 1702737.

[6] H. Kim, Y. Yun, Y. C. Lee, M. H. Lee, N. Saito, J. Kang, Jpn. J. Appl. Phys. 2018, 57, 1 .
[7] R. Yi, F. Dai, M. L. Gordin, S. Chen, D. Wang, Adv. Energy Mater. 2013, 3, 295.

[8] C. M. Park, J. H. Kim, H. Kim, H. J. Sohn, Chem. Soc. Rev. 2010, 39, 3115.

[9] A. Teichler, J. Perelaer, U. S. Schubert, J. Mater. Chem. C 2013, 1, 1910.

[10] N. C. Raut, K. Al-Shamery, J. Mater. Chem. C 2018, 6, 1618.

[11] G. Cadilha Marques, S. K. Garlapati, S. Dehm, S. Dasgupta, H. Hahn, M. Tahoori, J. A. Hagmann, Appl. Phys. Lett. 2017, 111.

[12] A. M. Gaikwad, D. A. Steingart, T. Nga Ng, D. E. Schwartz, G. L. Whiting, Appl. Phys. Lett. 2013, 102.

[13] R. Jung, M. Metzger, D. Haering, S. Solchenbach, C. Marino, N. Tsiouvaras, C. Stinner, H. A. Gasteiger, J. Electrochem. Soc. 2016, 163, A1705.

[14] F. Qu, G. She, J. Wang, X. Qi, S. Li, S. Zhang, L. Mu, W. Shi, J. Phys. Chem. Solids 2019, 124, 312

[15] A. Schiele, B. Breitung, A. Mazilkin, S. Schweidler, J. Janek, S. Gumbel, S. Fleischmann, E. Burakowska-Meise, H. Sommer, T. Brezesinski, ACS Omega 2018, 3, 16706.

[16] R. Yi, F. Dai, M. L. Gordin, H. Sohn, D. Wang, Adv. Energy Mater. 2013, 3, 1507.

[17] A. C. Ferrari, J. Robertson, Philos. Trans. R. Soc. A Math. Phys. Eng. Sci. 2004, 362, 2477.

[18] Y. Li, Z. Lin, G. Xu, Y. Yao, S. Zhang, O. Toprakci, M. Alcoutlabi, X. Zhang, ECS Electrochem. Lett. 2012, 1, A31.

[19] W. Wang, Z. Favors, C. Li, C. Liu, R. Ye, C. Fu, K. Bozhilov, J. Guo, M. Ozkan, C. S. Ozkan, Sci. Rep. 2017, 7, 1.

[20] T. Momma, T. Yokoshima, H. Nara, Y. Gima, T. Osaka, Electrochim. Acta 2014, 131, 195.

[21] J.P. Schmidt, T. Chrobak, M. Ender, J. Illig, D. Klotz, E. Ivers-Tiffée, J. Power Sources 2011, 196, 5342.

[22] V. J. Ovejas, A. Cuadras, Batteries 2018, 4, 43.

[23] R. Tatara, P. Karayaylali, Y. Yu, Y. Zhang, L. Giordano, F. Maglia, R. Jung, J. P. Schmidt, I. Lund, Y. Shao-Horn, J. Electrochem. Soc. 2019, 166, A5090.

[24] S. A. Singaraju, T. T. Baby, F. Neuper, R. Kruk, J. A. Hagmann, H. Hahn, B. Breitung, ACS Appl. Electron. Mater. 2019, 1, 8, 1538.

[25] G. C. Marques, S. K. Garlapati, D. Chatterjee, S. Dehm, S. Dasgupta, J. Aghassi, M. B. Tahoori, IEEE Trans. Electron Devices 2017, 64, 279.

[26] C. Erk, T. Brezesinski, H. Sommer, R. Schneider, J. Janek, ACS Appl. Mater. Interfaces 2013, 5, 7299

[27] G. Y. I. Kovalenko, B. Zdyrko, A. Magasinski, B. Hertzberg, Z. Milicev, R. Burtovyy, I. Luzinov, G. Yushin, Science. 2011, 334, 75.

Manuscript received: March 11, 2020

Revised manuscript received: April 23, 2020

Accepted manuscript online: April 27, 2020

Version of record online: 


\section{ARTICLES}

Powering printed electronics: Nano silicon ( $\mathrm{Si}$ ) is an attractive candidate for lithium-ion batteries (LIBs) in comparison to graphite, since it delivers 10 times more capacity than commercially available graphite electrodes. The carbon coated Si composites are demonstrated as a potential anode material for LIBs and possess stable capacity for $>100$ cycles. Our study found out that full cells fabricated with printed Si coated carbon composite anode are able to power the printed transistor circuitry.

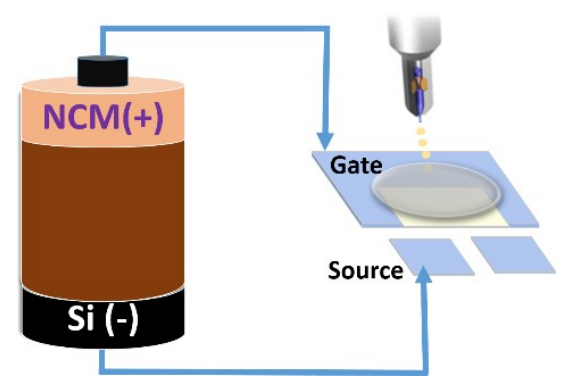

P. A. Sukkurji, Dr. I. Issac, S. A.

Singaraju, Dr. L. Velasco, Prof. J. A. Hagmann, Prof. W. Bessler, Prof. $H$. Hahn, Dr. M. Botros*, Dr. B. Breitung* $1-9$

Tailored Silicon/Carbon Compounds for Printed Li-Ion Anodes 